\title{
Title: Types of Episodic Disability among People Living with HIV in Zambia
}

\begin{abstract}
HIV is increasingly recognized as a chronic illness which may result in episodic disability related to effects of the virus, side effects of medication, co-morbidities and consequences of aging. Little is known about the episodic disability experiences of people living long-term with HIV in resource limited countries, which is best understood by following people over time. This qualitative longitudinal study examined the episodic disability experiences and the applicability of four types of episodic disability among people living with HIV and on antiretroviral therapy (ART) in Zambia. We interviewed 31 men and women living with HIV on three occasions at sixmonth intervals (total of 93 interviews) examining the processes of change over time. We used disability models to inform the interviews exploring impairments/symptoms, activity limitations and participation restrictions. Longitudinal analyses of transcribed interviews confirmed the applicability of four types over time: stable, increasing disability, decreasing disability and significant fluctuations. Analyses highlighted the extent to which determinants of health contributed to the disability experienced. Use of disability models revealed the importance of environmental and social influences on disability and quality of life. The indicators of type of episodic disability could be used clinically to help understand the nature and potential triggers of the episodes..
\end{abstract}

Keywords: HIV; episodic disability; longitudinal analysis; qualitative research

Word Count: 2,791 


\section{Introduction}

In high income countries in which people living with HIV (PLWH) are diagnosed early, and have long term retention and adherence to anti-retroviral therapy (ART), the life span of is nearing normal (Wandeler, Johnson, \& Egger, 2016). A similar trend in mortality rates has been observed in low income countries. (Katz \& Maughan-Brown, 2017). One consequence of living longer lives is the emergence of disability related to: the virus, side effects of medication, comorbidities, and the natural consequences of aging (Guaraldi et al., 2011). Disability models such as the International Classification of Function, Disability and Health (ICF) help to conceptualize environmental and contextual contributors to disability (World Health Organization [WHO], 2001). In the ICF, disability is viewed as impairments in body structure or function which limit activities of daily living and restrict social participation (WHO, 2001). Personal and environmental factors interact with the health condition to determine the level of an individual's function (WHO, 2001). Derived from the ICF, the Episodic Disability Framework demonstrates how the disability experienced by PLWH is often episodic in nature, associated with fluctuating periods of good and ill health (O’Brien, Bayoumi, Strike, Young, \& Davis, 2008; O’Brien, Davis, Strike, Young, \& Bayoumi, 2009). The Episodic Disability Framework was derived from the perspectives of PLWH living in Canada and was foundational to increasing understanding of the consequences of living with HIV as an episodic illness. It includes physical, mental, emotional and social domains and four dimensions of disability: symptoms/impairments, difficulties with day-to-day activities, challenges to social inclusion, and uncertainty or worrying about the future. Uncertainty resulting from this unpredictability is seen as an anxiety shaping everyday life of PLWH (Rosenfeld, Ridge, \& Von Lob, 2014). Uncertainty is also at the centre of a model of disability of those aging with HIV, impacting all components of disability 
including symptoms, day-to-day activities and social participation, and influenced by extrinsic contextual factors (e.g., stigma) and intrinsic contextual factors (e.g., age) (Solomon et al., 2018).

Studies exploring disability experienced by PLWH have largely been cross-sectional, thus limiting understanding of the episodic nature of HIV experienced over time. However, Solomon et al. (2018) conducted a longitudinal qualitative study of older adults living with HIV in Canada to address this knowledge gap. They identified four types of trajectories of episodic disability over time: increasing disability, decreasing disability, stable, and significant fluctuations. Increased understanding of an individual's episodic trajectory of disability over time could assist in tailoring treatment interventions. However, little is known about the experiences of living long-term with HIV as an episodic disability in resource-limited countries.

Our purpose was to examine the episodic disability experiences among PLWH and on ART in Zambia. We sought to understand the episodic nature of HIV and how the associated uncertainty shaped their disability experiences over time. In particular, we examined the applicability of the four types in a low resource setting.

\section{Methods}

We conducted a longitudinal qualitative study in Lusaka, Zambia, interviewing PLWH in one of three languages, (English, Bemba or Nyanja; (Squires, 2009) on three occasions at six-month intervals. Qualitative longitudinal methods focus on examining processes of change over time and why changes occur (Cordon \& Millar, 2007; Neale \& Flowerdew, 2003). Participants were eligible for the study if they were HIV-positive, 18 years or older, and on ART for at least six months. Participants were purposefully recruited from two health facilities: (1) the Chawama Health Centre, a public government-funded ART delivery facility and (2) the Lusaka Trust Hospital, a private ART facility. Recruitment varied by site. At the Chawama Health Center, the sister in charge and/or ART adherence counsellor identified potential participants through review of clinic 
records, who were then approached by clinic staff. At the Lusaka Trust Hospital the HIV physician identified and made initial contact with potential participants. All potential participants were referred to the Zambian research coordinator who provided additional information and ensured there was variation in gender, socio-economic status and length of time on ART. Participants were purposefully recruited based on sex, age and variation in time on ART. We aimed to have equal numbers of men and women, at least 10 participants over the age of 50 years.

Two rehabilitation frameworks informed the interview guide: the ICF (WHO, 2001) and the Episodic Disability Framework (O’Brien et al., 2008; O’Brien et al., 2009). In Round 1, participants shared experiences of living with HIV related to their body's functioning, day-to-day activities, and relationships at home, at work and in their communities. The interview guides for subsequent rounds were modified based on an inductive approach to reflect on concerns raised in previous interviews and changes that had occurred over time. Most of the interviews were conducted in person by our Zambian research assistant who was hired and trained specifically for this project. A small number were conducted by a Zambian co-investigator (VB) who is a British social scientist residing in Zambia.

Participants received an honorarium after each interview. Ethical approval was received from McMaster University, University of Toronto, University of Zambia and Ministry of Health, Republic of Zambia.

\section{Analysis}

Interviews were translated and transcribed into English as necessary and quality checked against the original audio file. NVivo 10 was used to facilitate analysis (REF ). Our structured approach for longitudinal analysis began by creating summary profiles for each participant, documenting issues with the three components of the ICF: impairments/symptoms, activity limitations and participation restrictions (WHO, 2001). We then tracked each issue over 
subsequent interviews, indicating whether it was new, remained the same between rounds, resolved, improved or deteriorated. We summarized contextual details, sources of uncertainty, and triggers of episodes. The result was a detailed summary that depicted the disability experienced over three rounds of interviews for each participant.

We constructed a table (Table 1) that described indicators of each of the four types based on the work of Solomon et al. (2018). Subsequently, three of the investigators (initials removed for blinding) independently reviewed three participants' files, summarized the trajectory of the participant's experience, assigned a type and stated the rationale for the assignment. These were derived qualitatively. As we were examining the applicability of four pre-determined types of disability, this component of the analysis was deductive in nature. We then reviewed the concordance between type assignment, reconciled differences through discussion and modified the table to provide clarity for future assignment. For example, we included an additional indicator related to stigma and disclosure. All investigators then used the modified table to assign a type to the remaining participants. Each participant was independently reviewed by a minimum of three investigators.

\section{Results}

Given the focus on exploring experiences over time, we included only participants interviewed on all three occasions. Thirty-one participants completed all rounds of interviews for a total of 93 interviews; four participants were excluded. Participant characteristics are shown in Table 2. Below, we describe the types in detail, providing an example of each. Note: some details have been altered to ensure anonymity.

\section{Stable over time}


Fifteen (48\%) of the participants were stable over time. They experienced fluctuations in impairments on a daily, weekly or less frequent basis; however, these were minimal and did not affect their everyday activities or participation. They described uncertainties related to employment, stigma and food security. However, they did not describe uncertainty related to their physical status. Rather, participants compared their current experiences with their more dire pre-ART situations. As one woman stated "[ART] gives me life and strength. It is not like when you have (are not on ART) then your life is over...". While considered "stable" many participants described precarious living situations and seemed at risk of progressing to the "increased disability" or "significant fluctuations" types. Participants discussed stigma which made it difficult to disclose at work and take time off for appointments. Fear of the consequences of HIV disclosure often limited social and instrumental supports, further contributing to their precarious situations.

Example: Participant A is a 54-year-old man diagnosed with HIV in 2012 and starting ART in 2012. He is recently divorced from his wife. He has 5 children living in his household. He works occasionally as a guard and requires flexibility in his work to access his ART. He describes "forgetfulness" and vision issues but there is little variation in his symptoms over time. He states, "I feel very fine" at Time 3 and does not describe any activity limitations. He is trying to make healthy choices by refraining from alcohol and sexual activity. His main concerns do not relate to HIV: "What I think a lot about is how I am living and how I will live in the future but I am not thinking about HIV...I'm thinking about how I (can make) a living." His challenges are being able to find enough work to support himself, food security for his family and being able to send his children to school, which generates uncertainty.

\section{Increasing disability or deteriorating over time}


Two (6\%) participants deteriorated over time. Increased disability was triggered by a stroke in both participants. While there were fluctuations in episodes of disability, there were few periods of "good" health and the overall picture was one of deterioration. This led to significant impairment that impacted activities and participation over the course of the study. One participant recovered from her stroke-related impairments but experienced greater participation restrictions. The other continued to deteriorate and died shortly after completion of the study.

Example: Participant B is a 56-year-old man diagnosed with HIV in 2004 and initiating ART in 2006. He is married to an HIV-negative woman and has many people living in his household. He describes myriad symptoms and activity limitations at Time 1. He describes how he lost his job due to HIV discrimination and is unemployed; he is actively searching for employment throughout the study. He discloses his status on job application forms and attributes this to his lack of ability to secure employment. He was active in his church, however his openness about his status caused challenges as the church "hasn't fully accepted people living with HIV". He had a stroke between Time 2 and Time 3 which contributed to his increased disability. His speech, hand function and walking are affected by the stroke. While his family is supportive, the stroke restricts his activities and social participation.

\section{Decreasing disability or improving over time}

Seven (23\%) of participants improved over time. They experienced symptoms such as fatigue or neuropathy, however these remained stable or improved and did not affect activities and participation. Improvements over time were often attributed to triggers. For example, some participants changed their ART regimens during the study, leading to improvement. Participants recognized these changes and were committed to their treatment regimens. One man stopped drinking alcohol which he attributed to his improvement over time. Although her impairments, 
activity limitations and participation restrictions remained the same, one woman's disclosure of HIV resulted in additional work supports which improved her quality of life. These participants were positive, had accepted their status and had satisfying relationships and social supports.

They experienced episodes of disability but accepted this as part of their lives. While participants in this type described uncertainties related to disclosure, employment and long-term availability of ART, they did not dwell on these, and described staying positive and being future-oriented. Example: Participant C is a 38-year-old widow, diagnosed with HIV in 2009 with initiation of ART in 2010. Her husband died 8 years prior to Time 1. She has 6 children and many people living in her household. She takes in laundry at home and does clerical work. She describes her only impairment as visual problems which appeared to be episodic and "had cleared" at Time 3. She does not identify any activity restrictions. Although she experienced stigma when she was first diagnosed she denies that this is a current issue. She has disclosed widely and has the support of her family, church, and employer (whose support enables her attend the clinic to get ART). She has a boyfriend that she had not disclosed to at Time 1. However, she discloses to him by Time 3 and she is hopeful that they will marry. She volunteers at the local clinic. She is proactive and positive saying, "I live my life to the fullest. I enjoy my life, I don't even have doubts about tomorrow."

\section{Significant Fluctuations in disability over time}

Seven (23\%) of the participants experienced significant fluctuations in disability over time describing a range of unpredictable impairments, activity limitations and participation restrictions. Access to social support varied over the course of the study. New impairments arose over time; some occasionally resolving or becoming worse. These fluctuations led to uncertainty, a hallmark of this type as indicated in Table 1. Participants described learning to live with their 
current situation and not planning for the future. This woman summarized her episodic experiences, "Sometimes you feel sick. Sometimes you feel tired or sometimes you feel you're not yourself. You're just somewhere, your mind is somewhere. You're just...why this? Why this...but life goes on."

Example: Participant D is a 50-year-old woman who was diagnosed with HIV in 2000 and initiated ART in 2007. She is a widow, with children and grandchildren. She works at the market but is unable to work at Time 2 due to leg pain. Fatigue, her most debilitating symptom, varies daily with activities. She is diagnosed with diabetes during the study, and experiences diabetes-related numbness in her hands that improves with new medications. Although her fatigue improves after starting diabetes medication at Time 2, by Time 3 she was paying someone to do her laundry as she was too tired to do it. She disclosed to immediate family members but is cautious about with whom she shares her status. She worries about dying and not being able to care for her children. She appears angry, believes that she could die anytime, and engages in passive coping: "God has control over whether I will die today or tomorrow."

\section{Discussion}

This study is the first to longitudinally examine the varied trajectories of episodic disability experienced by PLWH in a low-resource country. It builds on previous work by explicating indicators of four episodic disability types and demonstrating their applicability. Although younger than the over-50 Canadian cohort (Solomon et al., 2018) participants were able to be assigned to one of four types. Similar to the Canadian study, it highlights that while episodic disability is defined by fluctuating periods of illness and wellness, PLWH also experience positive trajectories that can be stable or improve over time. 
The majority of participants were consistent with a "stable" type. Participants' narratives frequently compared their present status with their often-dire situation prior to starting ART. Contrasting their experiences may help some participants remain positive and hopeful. Positive reappraisal strategies, such as coping by focussing on the benefits of past challenges or experiences, are associated with better psychological and physical outcomes in PLWH, albeit in a high-income country (Moskowitz, Hult, Bussolari, \& Acree, 2009).Future works should evaluate the feasibility and efficacy of incorporating positive reappraisal strategies in other contexts.

Not surprisingly, the sources of uncertainty varied from those perceived by PLWH in high income countries. Older PLWH in Canada experienced uncertainty related to understanding the source of their health challenges, worried about who would care for them in the future, whether appropriate long-term housing would be available and whether health providers had the knowledge and skills to care for them as they aged (Solomon et al., 2014b). Financial concerns were expressed by long-term survivors diagnosed early in the epidemic who did not plan on living a long life. In contrast, the Zambian participants' concerns often related to more immediate needs such food security, HIV stigma, and implications of disclosure. Uncertainty is a dimension of disability in the episodic disability framework (O’Brien et al., 2008) and is at the center of a model of disability derived from a grounded theory study of 49 adults living with HIV in Canada (Solomon et al., 2014a). Our findings suggest that uncertainty or worrying about the future, while present, may not be as central in low-income countries where more immediate needs related to determinants of health prevail.

Others have called for better integration of rehabilitation strategies into long-term care in sub-Saharan Africa (Hanass-Hancock, Myezwa, Nixon, \& Gibbs, 2015; Nixon et al., 2018). This 
study reinforces this need by showing that HIV disability is not static and fluctuates over time. Additionally, the need for a continuum of care for PLHW that prevents and mitigates disability has been recently highlighted in a study which showed that those with more disability do not have as much access to rehabilitation in South Africa (Myezwa et al, 2018). Thus, HIV management also needs to evolve to deal with the chronic and episodic nature of the illness that is emerging in low-income countries. Given resource constraints and potential challenges travelling due to poverty or mobility issues, home-care and community-based models of rehabilitation are needed (Hanass-Hancock et al., 2015).

This study is novel in that it focuses on understanding the nature of episodic disability by examining change in disability over time. Strengths include the longitudinal design and high retention rate of participants across interviews. Limitations include recruitment of participants who are able to access treatment and may represent a more mobile, healthier cohort of those living with HIV. Additionally, the duration of this study may not have been sufficient for some participants to experience change over time.

This study highlighted the extent to which determinants of health, such as food and income insecurity, contribute to the disability experienced. Despite being assigned a stable type, some participants faced very precarious life situations, largely due to job insecurity, potential loss of social support, fear of stigma, food insecurity and poverty. It reinforces the need to address strategies that go beyond ART testing and adherence to address contextual factors and environmental contributors to disablement. These findings also highlight the importance of using disability models such as the ICF and the Episodic Disability Framework to understand the importance of environmental and social influences on disability and quality of life. 
The indicators of types of episodic disability could be used clinically to help understand the nature of the episodes of disability and potential triggers experienced by PLWH. Increased understanding of the episodic trajectories may help to tailor interventions. Identifying those at risk for increasing disability or fluctuating trajectories may also help to proactively mitigate episodes of disability. Similarly, strategies to support and maintain those with a stable or decreasing disability for longer periods could promote better quality of life. Future research to quantitatively validate the indicators of the types in a larger sample is warranted. 


\section{Acknowledgements}

Funding: This work was supported by the Canadian Institutes of Health Research (grant \#114907). In-kind contributions were provided by The Zambia AIDS Related Tuberculosis

(ZAMBART) Project, International Centre for Disability and Rehabilitation (ICDR), Disability HIV and AIDS Trust (DHAT), Realize (formerly known as the Canadian Working Group on HIV and Rehabilitation), Lusaka Trust Hospital and Chawama Health Centre.

\section{Declaration of Interest Statement}

The authors report no conflicts of interest. 


\section{References}

Corden, A., \& Millar, J. (2007). Qualitative longitudinal research for social policy - Introduction to themed section. Social Policy and Society, 6(4):529-532.

Guaraldi, G., Orlando, G., Zona, S., Menozzi, M., Carli, F., Garlassi, E., ... Palella, F. (2011). Premature age-related comorbidities among HIV-infected persons compared with the general population. Clinical Infectious Diseases, 53(11), 1120-1126.

Hanass-Hancock, J., Myezwa, H., Nixon, S. A., \& Gibbs, A. (2015). "When I was not longer able to see and walk, that is when I was affected most": experiences of disability in people living with HIV in South Africa. Disability and Rehabilitation, 37(22), 2051-2060.

Katz, I. T \& Maughan-Brown, B. (2017). Improved life expectancy of people living with HIV: who is left behind? The Lancet HIV, 4(8), e324-e326.

Moskowitz, J. T., Hult, J. R., Bussolari, C., \& Acree, M. (2009). What works in coping with HIV? A meta-analysis with implications for coping with serious illness. Psychological Bulletin, 135(1), 121-141.

Neale, B., \& Flowerdew, J. (2003). Time, texture and childhood: the contours of longitudinal qualitative research (Working Paper 30). Leeds, UK: Centre for Research on Family, Kinship and Childhood.

Nixon, S. A., Bond, V., Solomon, P., Cameron, C., Mwamba, C., Hanass-Hancock, J., ... Yates, T. (2018). Optimism alongside new challenges: Using a rehabilitation framework to explore experiences of a qualitative longitudinal cohort of people living with HIV on antiretroviral treatment in Lusaka, Zambia. AIDS Care, 30(3), 312-317.

O’Brien, K. K., Bayoumi, A. M., Strike, C., Young, N. L., \& Davis, A. M. (2008). Exploring disability from the perspective of adults living with HIV/AIDS: development of a conceptual framework. Health and Quality of Life Outcomes, 6, 76.

O’Brien, K. K., Davis, A. M., Strike, C., Young, N. L, \& Bayoumi, A. M. (2009). Putting episodic disability into context: a qualitative study exploring factors that influence disability experienced by adults living with HIV/AIDS. Journal of the International AIDS Society, 12(1), 30 .

Rosenfeld, D., Ridge, D., Von Lob, G., \& on behalf of the HIV and Later Life Team. (2014). Vital scientific puzzle or lived uncertainty? Professional and lived approaches to the uncertainties of ageing with HIV. Health Sociology Review, 23(1), 20-32.

Solomon, P., O’Brien, K. K., Nixon, S., Letts, L., Baxter, L., \& Gervais, N. (2018). Trajectories of episodic disability in people aging with HIV: a longitudinal qualitative study. Journal of the International Association of Providers of AIDS Care, 17, 2325958218759210.

Solomon, P., O’Brien, K., Wilkins, S., \& Gervais, N. (2014a). Aging with HIV: A Model of Disability. Journal of the International Association of Providers of AIDS Care, 13(6), 519525. 
Solomon, P., O’Brien, K., Wilkins, S., \& Gervais, N. (2014b). Aging with HIV: The Role of Uncertainty. AIDS Care, 26(2), 240-245.

Squires, A. (2009). Methodological challenges in cross-language qualitative research: a research review. International Journal of Nursing Studies, 46(2), 277-287.

Wandeler, G., Johnson, L. F., \& Egger, M. (2016). Trends in life expectancy of HIV-positive adults on ART across the globe: comparisons with general population. Current Opinions in HIV and AIDS, 11(5), 492-500.

World Health Organization. (2001). The World Health Organization's International Classification of Functioning, Disability and Health (ICF). Geneva: World Health Organization. 
Table 1. Indicators of Episodic Disability Types

\begin{tabular}{|c|c|c|c|c|}
\hline Indicators & Stable & Increasing Disability & Decreasing Disability & Fluctuating \\
\hline $\begin{array}{l}\text { Symptoms } \\
\text { (impairment) }\end{array}$ & Little variation & New and/or worsening & $\begin{array}{l}\text { Fewer, no significant } \\
\text { or new }\end{array}$ & $\begin{array}{l}\text { New and/or significant } \\
\text { variation and } \\
\text { unpredictable }\end{array}$ \\
\hline Social Support & Level does not change & $\begin{array}{l}\text { Decrease in support } \\
\text { and increase in social } \\
\text { isolation }\end{array}$ & $\begin{array}{l}\text { Has access to } \\
\text { adequate social } \\
\text { support which may } \\
\text { have increased over } \\
\text { time }\end{array}$ & $\begin{array}{l}\text { No consistent access } \\
\text { to social support, } \\
\text { unpredictable and } \\
\text { fluctuating }\end{array}$ \\
\hline Activity & $\begin{array}{l}\text { Maintains activity } \\
\text { levels }\end{array}$ & $\begin{array}{l}\text { Decrease in activity } \\
\text { levels or number of } \\
\text { activities }\end{array}$ & $\begin{array}{l}\text { Increase in activity } \\
\text { levels or number of } \\
\text { activities }\end{array}$ & Varies unpredictably \\
\hline $\begin{array}{l}\text { Uncertainty and } \\
\text { worrying about the } \\
\text { future }\end{array}$ & $\begin{array}{l}\text { No change in level of } \\
\text { uncertainty } \\
\text { Does not mention or } \\
\text { dwell on uncertainty }\end{array}$ & $\begin{array}{l}\text { Future is } \\
\text { unpredictable \& } \\
\text { uncertain }\end{array}$ & $\begin{array}{l}\text { Has strategies to } \\
\text { mitigate or cope with } \\
\text { uncertainty }\end{array}$ & $\begin{array}{l}\text { Fluctuating } \\
\text { Uncertainty is a } \\
\text { hallmark of this type } \\
\text { and is pervasive }\end{array}$ \\
\hline Participation & $\begin{array}{l}\text { Maintains } \\
\text { participation }\end{array}$ & $\begin{array}{l}\text { Loss of roles and/or } \\
\text { giving up pursuits } \\
\text { and/or inability to } \\
\text { perform }\end{array}$ & $\begin{array}{l}\text { Taking on new roles } \\
\text { or pursuits }\end{array}$ & $\begin{array}{l}\text { Variable \& changing } \\
\text { over time, but limited } \\
\text { participation } \\
\text { Social participation is } \\
\text { affected by stigma } \\
\text { and/or fear of } \\
\text { disclosure }\end{array}$ \\
\hline $\begin{array}{l}\text { Identified } \\
\text { management/coping } \\
\text { strategies }\end{array}$ & $\begin{array}{l}\text { Acceptance and } \\
\text { positive attitude }\end{array}$ & $\begin{array}{l}\text { Passive coping or } \\
\text { absence of coping }\end{array}$ & $\begin{array}{l}\text { Has positive coping } \\
\text { strategies, acceptance } \\
\text { and active engagement } \\
\text { in problem solving }\end{array}$ & $\begin{array}{l}\text { Learning to live with } \\
\text { or stopped planning } \\
\text { for future }\end{array}$ \\
\hline Stigma and disclosure & $\begin{array}{l}\text { Remains the same/no } \\
\text { new reported incidents } \\
\text { of stigma }\end{array}$ & $\begin{array}{l}\text { Stigma and fear of } \\
\text { disclosure limit access } \\
\text { to support and affects } \\
\text { activities and } \\
\text { participation }\end{array}$ & $\begin{array}{l}\text { Has strategies to } \\
\text { minimize stigma } \\
\text { and/or advocates for } \\
\text { PLWH }\end{array}$ & $\begin{array}{l}\text { Activities and } \\
\text { participation are } \\
\text { variably affected by } \\
\text { fear of disclosure and } \\
\text { stigma }\end{array}$ \\
\hline
\end{tabular}


Table 2. Participant Characteristics at the Time of Recruitment

\begin{tabular}{|l|c|c|c|}
\hline \multicolumn{1}{|c|}{ Category } & $\begin{array}{c}\text { Chawama (CHC) } \\
(\mathbf{n = 2 6})\end{array}$ & $\begin{array}{c}\text { Lusaka Trust (LTH) } \\
(\mathbf{n = 5})\end{array}$ & $\begin{array}{c}\text { Overall } \\
(\mathbf{n = 3 1})\end{array}$ \\
\hline Age (years) & $21-53$ & $36-51$ & $21-53$ \\
Average: 40 & Average: 42 & Average: 40.3 \\
\hline Sex & 15 women & 2 women & 17 women \\
Time on treatment & 11 men & 3 men & 14 men \\
\hline years) & $1-9$ & $6-12$ & $1-12$ \\
\hline Average: 5 & Average: 9.6 & Average: 5.7 \\
\hline & 4 English & 5 English & 9 English \\
& 14 Nyanja & & 8 Nyanja \\
& 8 Bemba & & \\
\hline
\end{tabular}

